Narváez, V. y Oviedo, J. (2020), Imperio, financiarización y los nuevos centros de producción normativa contable. Contaduría Universidad de Antioquia, 76, 75-95.

Doi:https://doi.org/10.17533/udea.rc.n76a06

\title{
Imperio, financiarización y los nuevos centros de producción normativa contable
}

Viviana Patricia Narváez Castillo vnarvaez@unicauca.edu.co

Universidad del Cauca

Orcid: 0000-0001-6239-0778

Juan Ignacio Oviedo Pino jioviedo@unicauca.edu.co

Universidad del Cauca

Orcid: 0000-0002-0548-9699 
Imperio, financiarización y los nuevos centros de producción normativa contable

Resumen: En el contexto de un mundo globalizado, crecientemente complejo, en el que todo está sujeto a permanente transformación, la contabilidad como disciplina no está exenta de sufrir los embates derivados de los nuevos tiempos, que no dejan de sorprender con sus conflictos, crisis y paradojas. El presente artículo se inscribe dentro de esta trama de complejidades, y se pretende abordar una aproximación analítica que dé cuenta precisamente de cómo el contexto económico ha impactado profundamente la contabilidad y los centros de producción normativa contable, especialmente en el proyecto moderno de economía de mercado y más especificamente en los tiempos de exacerbación de la acumulación rentística financiera que caracteriza el último periodo del capitalismo.

Palabras clave: contabilidad, financiarización, imperio, regulación contable.

\section{Empire, financialization and the new accounting regulation production centers}

Abstract: In the context of a globalized, increasingly complex world, in which everything is subject to constant transformation, accounting as discipline is not exempt from suffering the attacks proper of the current times, which continue to surprise us with their conflicts, crises and paradoxes. The present paper is inscribed within this weave of complexities, and seeks an analytical approach that precisely accounts for how the economic context has deeply influenced accounting and the accounting regulation production centers, especially in the modern project of market economy and more specifically in times of the exacerbation of financial income accumulation characterizing the last period of capitalism.

Keywords: Accounting, financialization, empire, accounting regulation

\section{Império, financeirização e os novos centros de produção normativa contábil}

Resumo: No contexto de um mundo globalizado, cuja complexidade aumenta constantemente, no que todo está sujeito a permanente transformação, a contabilidade como disciplina não está isenta de sofrer os embates derivados dos novos tempos, que não deixam de surpreender com os seus conflitos, crises e paradoxas. O presente artigo inscreve-se dentro desta trama de complexidades, com o que se pretende abordar uma aproximação analítica que dê conta justamente de como o contexto econômico tem impactado profundamente a contabilidade e os centros de produção normativa contábil, especialmente no projeto moderno de economia de mercado e mais especificamente nos tempos de exacerbação da acumulação rentista financeira que caracteriza o último período do capitalismo.

Palavras chave: Contabilidade, financeirização, império, regulação contábil.

\section{Empire, financiarisation et nouveaux centres de production normative comptable}

Résumé: dans le contexte de la mondialisation, de plus en plus complexe, où tout est sujet à des transformations permanentes, la comptabilité en tant que discipline n'est pas à l'écart des assauts dérivés des nouveaux temps qui ne cessent pas de surprendre avec leur conflits, crises et paradoxes. Cet article s'inscrit dans ce réseaux de complexités, et vise à traiter une approche analytique qui rende compte justement de la façon dans laquelle le contexte économique a fortement affecté la comptabilité et les centres de production normative comptable, en particulier dans le projet moderne d'économie du marché, et plus précisement dans le temps d'exarcerbation de l'accumulation de la rente financière caractéristique de la dernière période du capitalisme.

Mots clés: comptabilité, financiarisation, empire, régulation comptable. 


\title{
Imperio, financiarización y los nuevos centros de producción normativa contable
}

\author{
Viviana Patricia Narváez Castillo, Juan Ignacio Oviedo Pino. \\ https://doi.org/10.17533/udea.rc.n76a06
}

Primera versión recibida en septiembre de 2019 - Versión aceptada en marzo de 2020.

\section{Introducción}

A partir del último cuarto del siglo pasado, profundos cambios se han presentado en el escenario económico capitalista que, directa o indirectamente, han afectado a la sociedad en general. Auspiciados por el ascenso de las tecnologías de la información y de la comunicación, los intercambios y transacciones económico-financieras han requerido un lenguaje común que permita la armonía de los flujos, los cuales, con la entrada en vigor de la financiarización1 de la economía, reclaman la apertura de fronteras para movilizarse hacia donde las condiciones le sean favorables.

Ante las incesantes innovaciones mercantiles y financieras, la información derivada de ello ha desbordado la capacidad de los Estado-nación para regular eficaz y oportunamente estas prácticas, por lo cual organismos privados supranacionales, con la complacencia de los Estados, han asumido el rol de reguladores bajo una lógica de mercado. La contabilidad no ha sido ajena a estas nuevas dinámicas en las que la Nueva Arquitectura Financiera Internacional (NAFI) direcciona las políticas de información a revelar, condicionando la contabilidad bajo el paradigma de la información para la toma de decisiones.

El presente trabajo pretende develar cómo estos organismos han desplazado el papel regulador de los Estados-nación, consolidando centros de estandarización y regulación internacional que, para el caso de la contabilidad, han moldeado la información a revelar acorde con las exigencias de una economía financiarizada y de predicciones por encima de los requerimientos

1 Definida como el "ascenso de la importancia del capital financiero dentro del funcionamiento económico" (Medialdea y Sanabria, 2013, p. 195) 
Narváez, V. y Oviedo, J. Imperio, financiarización y los nuevos centros de producción normativa contable

de información por parte de administradores y otros interesados en el objeto social de las empresas.

La presente investigación con enfoque cualitativo tiene como intencionalidad analizar desde un contexto holístico e histórico el devenir de las nuevas formas de gobierno y desde una lógica inductiva-deductiva busca conectar estos hallazgos documentales con la NAFI y los organismos de regulación contable internacional, para explicar la contabilidad en el paradigma de la información para la toma de decisiones.

\section{El Imperio como forma global de soberanía}

Durante mucho tiempo la narrativa económica, especialmente después de la primera guerra mundial, hizo referencia, según la acepción leninista, al imperialismo como fase superior del capitalismo, cuyo itinerario para su configuración lo describe Ilich con la siguiente cronología:

1) Décadas de 1860 y 1870: cénit del desarrollo de la libre competencia. Los monopolios están en un estado embrionario apenas perceptible.

2) Tras la crisis de 1873, largo período de desarrollo de los cárteles, que son todavía una excepción. No están aún consolidados, son todavía un fenómeno pasajero.

3) Auge de finales del siglo XIX y crisis de 1900-1903: los cárteles se convierten en un fundamento de la vida económica. El capitalismo se ha transformado en imperialismo (1975, p. 19).

Ese imperialismo constituyó la expansión del Estado-nación, especialmente norteamericano, implantando un poder omnímodo a través del criterio de empresa monopólica que extendía sus tentáculos por el mundo entero.

De ese imperialismo tradicional, que ejercía un poder unívoco y negativo, se ha pasado a un nuevo orden económico: el Imperio. Un renovado poder reticular y sutil que redefine el concepto de soberanía global mediada por una serie de organismos nacionales y supranacionales unidos por una única lógica de dominio. A diferencia del imperialismo, el Imperio no tiene un lugar o centro reconocible de poder; por el contrario, su objetivo es el dominio de la vida social en su totalidad: "el control de la sociedad sobre los individuos no se ejerce solamente a través de la conciencia o la ideología, también se ejerce en el cuerpo y con el cuerpo. Para la sociedad capitalista, lo más importante es la biopolítica, lo biológico, lo somático, lo corporal" (Hardt y Negri, 2002, p. 39). En este sentido, la producción biopolítica, entendida como la producción de la vida misma en sociedad, superpone lo económico, lo político y lo cultural en los procesos de creación de riqueza.

El Imperio no está descrito en términos de un momento histórico o que marque una época determinada; su despliegue implica recrear un presente perpetuo; no constituye un gobierno específico sobre un territorio en 
particular, sino una forma de poder libidinal creador de realidad; esto es, el Imperio crea permanentemente el mundo que habita; es decir, con el Imperio se crea ante todo una ontología: una forma de ser y de estar en el mundo. Así las cosas, con este concepto emerge una suerte de "no lugar", un espacio descentrado y desterritorializado. Sobre esta arquitectura lisa el Imperio crea un entorno global o globalización de nuevo cuño, que interconecta, comunica, asimila, resignifica, distintos lugares y territorialidades, sintonizándolos con nuevos dispositivos y tecnologías de gobierno.

La construcción del nuevo orden, no reside como muchos suponen desde las ciencias sociales, en la centralidad hegemónica de los Estados Unidos en el marco de la globalización, aunque esta ocupe un estado de privilegio dentro del Imperio. El imperialismo ha terminado, sentencian los autores. Ninguna nación, por poderosa que parezca, podrá arrogarse este rol, pues si algo caracteriza este nuevo escenario es su falta de fronteras y territorialidades fijas.

Con la emergencia del Imperio se ha reconfigurado la geografía mundial del poder; los Estados-nación han sufrido un proceso de trasformación caracterizado por un marcado declive en sus capacidades de regulación y la formación de un nuevo orden institucional privado. La soberanía de los Estados-nación fue otrora la piedra angular de los imperialismos construidos por las potencias europeas, en la que los territorios y los límites geográficos delimitaban el centro del poder. Las fronteras y barreras establecidas en los territorios controlaban los flujos de producción y circulación de personas; con el control de los territorios todo el mapa global podía ser parcelado, codificado y conquistado. No obstante, la globalización imperialista de otros tiempos ha sido desplazada, los límites y fronteras geográficas han sufrido un proceso de borramiento, con el cual se ha pasado de un espacio estriado a un espacio liso (Deleuze y Guattari, 2002). La geografía mundial ha sufrido una total transformación.

Contrario a la lógica con la que operaba el mercado en los regímenes de soberanía del imperialismo, en esta nueva fase se encuentra un capitalismo que ruptura todos los límites geográficos sin depender de un centro de poder, expandiéndose de esta forma por todos los territorios, es un proceso que ha tenido lugar tanto en el contexto nacional como a escala mundial. Los incesantes flujos trasnacionales de capital y mercancías han propiciado que los Estado-nación se tornen inoperantes para regular los intercambios económicos y culturales a nivel global. Los regímenes y la soberanía de los Estados-nación han sufrido diversas mutaciones que llevaron a la consolidación de un nuevo orden mundial, desembocando en el desplazamiento progresivo de la soberanía del Estado Hegemónico, tal como lo exponen Hardt y Negri (2002):

Ciertamente es verdad que, frente al proceso de globalización, la soberanía de los Estados-naciones, aunque aún es efectiva, ha declinado progresivamente. Los factores 
Narváez, V. y Oviedo, J. Imperio, financiarización y los nuevos centros de producción normativa contable

primarios de la producción y el intercambio -dinero, tecnología, gente y bienes- se mueven con creciente facilidad a través de los límites nacionales; por lo que el Estadonación posee cada vez menos poder para regular estos flujos e imponer su autoridad sobre la economía. Incluso los Estado-nación más poderosas ya no pueden ser consideradas como autoridades supremas y soberanas, tanto fuera como dentro de sus propias fronteras. (p. 4)

Con esta nueva geografía de poder surgen nuevos centros de producción normativa que vienen ya no necesariamente de la esfera pública sino del mundo del poder privado para posteriormente instalarse en el dominio de lo público, contribuyendo a la desnacionalización de los históricos programas nacionales característicos del keynesianismo. No obstante, esta reconfiguración del poder global no significa la caída o el fin de los Estados, pero es una realidad que estos ya no son el centro de la configuración del poder global.

\section{Privatización del derecho público y nuevos centros de producción normativa contable}

La globalización y mundialización de la economía, más allá de traspasar fronteras geográficas, ha conducido a una reconfiguración de la división entre la esfera pública y privada; es así como a partir de 1990 se observa con mayor fuerza la expansión del dominio de actores privados que, paulatinamente, han adquirido poder a través de la absorción de funciones propias de los Estados generando un reordenamiento de elementos públicos y privados, el cual ha sido direccionado en gran medida a generar condiciones óptimas para el desarrollo de las operaciones globales de los mercados y las empresas. Una de las funciones propias del estado que ha virado significativamente hacia la esfera privada es la de regulación y creación de normas, función que los gobiernos vienen compartiendo desde hace varios años con organismos del sector privado y que se ha acentuado con el fortalecimiento del capitalismo y el auge de la financiarización de la economía mundial.

Con el desarrollo de los nuevos procesos de acumulación basados en la lógica del capitalismo financiero donde existe una transformación de las ganancias en rentas, los Estados se tornan incapaces de regular la gran cantidad de capital y de transacciones económicas que se realizan por segundo a nivel global, lo que ha ocasionado un desplazamiento de su función reguladora hacia agentes privados que crean normas y reglas con el fin de administrar ciertos estamentos que eran exclusivos del gobierno estatal. Los Estados Nacionales han optado por desnacionalizar gran parte de sus marcos jurídicos (Sassen, 2010). No obstante, esto no implica que el aparato estatal esté desapareciendo, sino que se han generado variantes entre la función reguladora de los Estados y los agentes privados, estas variantes según Schwarcs (2002) pueden ir desde normas que se originan en el gobierno y son adoptados por los actores privados 
hasta normas que son originadas por agentes privados pero que son aplicadas y adoptadas por el gobierno.

El papel que vienen cumpliendo los actores privados se ha consolidado como un factor clave para la reconfiguración en materia de regulación internacional; es así como los agentes privados participan cada vez más en la creación de instituciones y normas que regulan la economía global con el objetivo de fijar sistemas a nivel mundial que permitan el óptimo desarrollo de los mercados y flujo de capitales; todo esto se lleva a cabo mediante la elaboración de acuerdos intergubernamentales que determinan elementos básicos de regulación. De esta manera, con la globalización económica las entidades privadas toman protagonismo mediante la captura del Estado (corporatocracia) (Franco, 2015), la cual se evidencia en la práctica paulatina y generalizada de incorporar en las leyes del Estado (sujeto pasivo) normas creadas y aplicadas inicialmente por los actores privados (sujetos activos). Con esto, el derecho termina por servir a la economía transformándose en un instrumento para la eficacia de los mercados y salvaguarda de los intereses privados de ciertos sectores, creando jurisprudencia ad hoc, paralela a los ordenamientos jurídicos locales (Burgos, 2000).

A este tipo de "privatización jurídica" o "neoliberalización del derecho" se le ha dado legitimidad mediante el llamado derecho comercial global -Lex Mercatoria- que, en el campo económico, ha erosionado las soberanías nacionales implantando una ecúmene jurídica internacional (De Sousa Santos, 1998). No obstante, la asimetría normativa podría disminuir la pertinencia y dificultar la aplicación local. Con el derecho al servicio de la economía, los Estados facilitan el desarrollo de los mercados globales, permitiendo a empresas extranjeras operar en sus territorios, situación que posibilita la internacionalización de los mercados, consolidando al Estado como un espacio clave para el desarrollo de condiciones óptimas en el proceso de globalización económica empresarial.

Es así como se viene instaurando en los últimos años un sistema económico global interconectado mediante los mercados financieros con la participación de los Estados junto a actores privados y organismos multilaterales especializados (Gómez, 2016), que se consolidan como redes intergubernamentales y que emiten una cantidad cada vez mayor de normas y reglamentaciones sobre asuntos relacionados con la globalización de los capitales y la consolidación de un nuevo orden comercial a nivel mundial.

La apropiación regulativa por parte de agentes de naturaleza privada, en la segunda mitad del siglo XX e inicios del XXI, ha sido uno de los fenómenos más dinámicos de la expansión del capitalismo global, colocando el derecho al servicio de la economía y no de la política, como bien lo describe Sassen (2010) al referirse a esta intromisión consignada en las directrices de política del Banco Mundial: 
El Banco Mundial considera que es fundamental separar el derecho de la política, colocando el primero al lado de la economía. Por esta vía, queda definido el papel sustantivo que el derecho debe cumplir en la definición de las cuestiones económicas globales, en detrimento de las funciones que cumplía otrora relacionadas con la resolución de los conflictos sociales. En la medida en que el discurso sobre el desarrollo se formula con un léxico jurídico, muchas de las decisiones institucionales y de los valores que suponen la reforma del mercado y los proyectos de desarrollo desaparecen bajo el lenguaje aparentemente neutral y técnico del derecho. (p. 275)

Del modelo estatal centralista, imbuido de cierto poder soberano hasta la segunda mitad del siglo XX, en el cual el propio Estado era un agente financiero que regulaba el mercado, se pasa a otro modelo agenciado por las políticas neoliberales, en donde el mercado global es el que gobierna y, por tanto, implanta formas de desregulación y de regulación, así como una transformación de las relaciones con el Estado.

La convergencia entre agentes reguladores se ha convertido en los nuevos centros de producción normativa a nivel global, puesto que, con el incremento del comercio internacional y el incesante flujo de capitales que se mueven producto de la financiarización, se ha incrementado la necesidad de crear normas y estándares internacionales basados en la lógica de la expansión de los mercados. Una de las redes intergubernamentales que más se ha fortalecido en los últimos años es la de los organismos que se mueven alrededor de la NAFI.

La NAFI constituye un conjunto de organizaciones y estándares, los cuales propenden por lograr una estabilidad financiera en el mundo, con el objetivo de contener la posibilidad de crisis nacionales. La Arquitectura Financiera Internacional tiene que ver directamente sobre el sistema de regulación y supervisión del sistema financiero internacional. El término NAFI está atado, entonces, a la evolución ocurrida desde el G-7 hacia el G-20 y la evolución del Foro de Estabilidad Financiera (FSF por sus siglas en inglés) hacia La Junta de Estabilidad Financiera (FSB por sus siglas en inglés). Según Eichengreen (1999), el objetivo principal de la NAFI es predecir, prevenir y resolver mejor las crisis financieras mediante reformas a las instituciones, a las estructuras y a las políticas.

La FSB es una de las entidades más importantes en la NAFI, fue creada en abril de 2009 en la cumbre de líderes del G-20 en reemplazo del anterior FSF. La razón de ser de la FSB es la de coordinar el trabajo de las autoridades financieras nacionales y de organismos internacionales responsables de la estabilidad financiera, las instituciones financieras internacionales, el sector de agrupaciones internacionales de reguladores y supervisores, y los comités 
de expertos de los bancos centrales. La FSB ha considerado un conjunto de estándares bajo el argumento que generan efectos beneficiosos sobre la estabilidad del sistema financiero a nivel nacional y mundial.

El conjunto de estándares emitidos por la NAFI comprende tres grandes grupos: política macroeconómica y trasparencia de datos (estadísticas); regulación y supervisión financiera; infraestructura institucional y de mercado. Entre los estándares de regulación y supervisión financiera emitidos se encuentran las Normas Internacionales de Información Financiera (NIIF).

Asistimos, de esta manera, a una suerte de gubernamentalización del Estado por el mercado; por supuesto esta transformación acarrea modificaciones profundas en cuanto a la racionalidad, funcionalidad y operatividad de la disciplina contable, la cual se ajusta a la racionalidad neoclásica y la moderna teoría financiera (Pardo, 2017).

Se ha virado de una regulación contable de naturaleza pública, que partía de los desplazamientos territoriales sobre los Estado-nación de los capitales, propios de las fases mercantilista e industrial, hacia una regulación financiera globalizadora de naturaleza privada debido a que, fundamentalmente, los flujos adquieren la facultad de la ubicuidad tanto territorial como extraterritorial; el mundo es cubierto por un dispositivo red (Castells, 2000) que permite desarrollar actividades y transacciones económico-financieras en tiempo real de un punto a otro del planeta en los que los Estados-nación no tienen la capacidad de regular tales relaciones, permitiendo la suplantación por organizaciones trasnacionales en materia de regulación. Se evidencia de esta manera la formación de una creciente internacionalización de relaciones de poder, cuyo eje y centralidad lo constituyen agencias encargadas de diseñar regulaciones de naturaleza privada encaminadas a prohijar una gobernabilidad global sustituyendo las legislaciones locales y sus singularidades. Esto explica la influencia ejercida sobre las regulaciones contables por las relaciones de poder globales en la estructuración de marcos de referencia encaminados a homogeneizar y estandarizar las prácticas disciplinarias y profesionales de la contabilidad.

\section{Geopolítica del conocimiento y regulación e investigación contable}

Cuando el filósofo argentino Walter Mignolo (1993) aborda la noción de la colonialidad del saber, enfatiza que entre la división geopolítica del mundo y el orden epistémico existe una relación intrínseca que atribuye a los lugares y a los sujetos una capacidad cognoscitiva y un poder de enunciación que corresponde con la colonialidad del poder. El proyecto moderno de ciencia ha vendido la idea de la neutralidad del conocimiento; este postulado parte de la concepción de Maquiavelo que aspira a desarrollar una ciencia y una tecnología 
Narváez, V. y Oviedo, J. Imperio, financiarización y los nuevos centros de producción normativa contable

libres de valores y, por supuesto, de los contextos en donde se produce. La contabilidad como disciplina de las cuentas y como instrumento de racionalidad del capital no ha escapado de los contextos, de las relaciones de poder y de los lugares desde donde se enuncian sus teorías o postulados conceptuales; por el contrario, estos han constituido el soporte epistémico desde donde se validan esos saberes y se subalternizan e invisibilizan otros. Se podría desde una perspectiva sintética definir un itinerario de desplazamiento de ese locus enunciativo, siguiendo a Oscar Feudal y Hernán Linares (2006), en los siguientes términos:

Destacamos en primera instancia el protagonismo de los autores Italianos, que iniciarían su aporte con la publicación del tratado de Luca Pacioli a finales del siglo XV, seguido por una cantidad importante de reconocidos autores de la época, contribución significativa que se asocia al poderío mundial de Italia en cuanto al comercio internacional, el cual finalizaría a mediados del siglo XVII a raíz de la decadencia Italiana, acentuada de una parte por las guerras e inestabilidad política, y de otra, tal vez con más trascendencia, por el descubrimiento y consolidación del comercio con el nuevo mundo.

Posteriormente, hasta mediados del siglo XIX, el protagonismo de la literatura contable pasaría a manos de los autores franceses, quienes se hicieran notar principalmente por la calidad e influencia de sus obras, con la valiosa contribución realizada por autores como Samuel Ricard, Bertrand François Barreme y Edmond Degranges padre, entre otros.

Finalmente, el protagonismo de la literatura contable se consolidaría en territorio Norte Americano, donde se le puede ubicar en la actualidad asociado principalmente al dominio de la economía mundial por parte de esta potencia, con un enfoque normativo evolucionado a partir de la crisis de 1929 y la depresión de los años 30, y consolidándose finalmente frente a los grandes escándalos financieros originados a principios de este siglo por importantes transnacionales de este país (pp. 8-9).

En esta línea, esa locación epistémica, en principio, estuvo referida a las escuelas de pensamiento contable de corte patrimonialista, pero una vez el interés de la acumulación de capital mutó desde la producción material a la especulación rentística, la regulación y estandarización normativa invadieron el ámbito contable y el lugar de enunciación o modo particular desde donde se produce el conocimiento y las reglas de aplicación también se desplazaron hacia estructuras de regulación privada, sustituyendo el interés público de la sociedad por el interés público de los usuarios de la información bursátil. Esta variación de la política regulativa está en estrecha consonancia con el desplazamiento de la geopolítica del conocimiento contable, la cual debe servir a las transformaciones que propician las nuevas necesidades de acumulación del capital global.

Bien lo advierte David Slater (2008): 
...los principales factores que marcan las agendas son presiones del mercado que a su vez están reemplazando la legislación política, y mientras que el espacio geográfico se mantiene como hogar de la política, el capital y la información habitan un ciberespacio en el cual el espacio físico se ve neutralizado (p. 338).

Por otra parte, no puede olvidarse el condicionamiento que impone la racionalidad tecno-económica dominante sobre todos los aspectos de la vida. Las crisis recurrentes del sistema de acumulación capitalista han ido delineando una agenda que se ajusta a los vaivenes, turbulencias y a las variables que imponen los gobiernos y las agencias, en términos de la política macroeconómica, para hacer posible paliar esas inestabilidades sistémicas; es por ello que como lo sugieren Jhon Cortés y Harold Álvarez (2018):

En las décadas de 1970 y 1980, por decisión de los líderes políticos de las naciones más poderosas, entre ellas, Inglaterra, EEUU y Alemania (Chesnais, 2003), el mundo da un viraje en lo económico hacia la liberación de los mercados y en la ruta de aplicar los postulados emergidos, décadas antes, de la corriente neoclásica de la economía, que en la práctica se condensa en ciertos programas de conducta impuestos y vigilados por los mencionados organismos trasnacionales, FMI y BM, respaldados y dirigidos por esas poderosas naciones. El Consenso de Washington y las normas impuestas por las instituciones de la NAFI son una buena muestra de ello. Con estos y otros instrumentos, esos organismos multilaterales aconductan al mundo, sobre todo al de las débiles naciones subdesarrolladas, imponiéndoles duras condiciones macroeconómicas y financieras, en garantía de su permanencia en el mundo viable a sus intereses (p. 63).

Lo que se trasluce de estas declaraciones de los gobiernos y las agencias metropolitanas es que la "historia" del conocimiento está marcada geohistóricamente, en tanto este es fabricado e impuesto desde los centros de decisión globales.

Las transformaciones contextuales acaecidas después de la segunda postguerra variarán el andamiaje económico-financiero global que, en esencia, hace referencia al primado de la financiarización por sobre la producción material, situación que llevará a la academia fundamentalmente metropolitana anglosajona a cambiar el enfoque del beneficio por el de información útil al usuario. Ya no será necesario, para esta corriente, preocuparse por una teoría general de la contabilidad o por utilizar herramientas metodológicas y epistemológicas que validen sus postulados, sino simplemente plegarse a un criterio eminentemente pragmático e inductivo de la utilidad de la información que sirva a los usuarios externos, principal y fundamentalmente vinculados a los mercados financieros.

Este viraje se explica, igualmente, desde la evolución del concepto de empresa que ha pasado de lo operativo e interno (fábrica), hacia la gestión de servicios o externo (firma); pero que, de manera normativizada ha dado en llamarse entidad que informa (IASB, 2018). El objeto social va a tener una 
sustancial redefinición, en tanto que en la era fordista se propendía por obtener y acopiar recursos de cara a ampliar la capacidad productiva de la organización, invirtiendo en activos físicos y desarrollos tecnológicos, en dirección a potenciar las capacidades productivas generando retornos en utilidades y mayor capacidad instalada, en la época de la financiarización, el objetivo de la firma ya no estará compelido a maximización de utilidades, a partir de las transformaciones productivas, sino a maximizar el valor para el accionista inversor, privilegiando las ganancias bursátiles mediadas por la gestión del riesgo financiero y potenciándolas a partir del apalancamiento financiero. De aquí se deriva que existan dos dimensiones que subyacen a los modelos de contabilidad: una soportada en la teoría de la propiedad y otra en la teoría de la entidad. En la primera, quien invierte es el dueño, que está íntimamente vinculado patrimonialmente a ella; en consecuencia, los informes se preparan para satisfacer los requerimientos ineludibles con los cuales, se supone, direcciona y ejecuta el objeto social; en cambio en la teoría de la entidad, los requerimientos informativos son independientes de sus eventuales propietarios, pues los avatares contingenciales de la volatilidad financiarizada tensionan la relación información-propietario.

Será en la década de 1970 y subsiguientes cuando, fundamentalmente desde los Estados Unidos, el planteamiento de la utilidad de la información financiera para diferentes usuarios adquirirá pleno auge, especialmente en los círculos gremiales y académicos de la potencia anglosajona. Por supuesto, que el locus enunciativo de esta concepción está emparentado con la potenciación y preminencia de los mercados bursátiles derivados de nuevas formas de acumulación rentística, los cuales para su funcionalidad a nivel planetario reclaman el perfeccionamiento de estructuras regulatorias y estandarizadoras en el modelo contable. La réplica y la forma de implementación del modelo empírico de investigación, particularmente en los Estados Unidos, estuvo mediado por lo que Tua (1991) denomina efectos multiplicadores, que no son otra cosa que dispositivos académicos financiados desde este centro hegemónico de producción normativa, los cuales hacen referencia a:

- $\quad$ Reforma de los planes de estudio (1959-1960).

- Nacimiento de revistas especializadas en investigación empírica.

- Celebración de conferencias y congresos sobre investigación empírica.

- Existencia de bancos de datos.

- Disponibilidad de fondos para financiar la investigación.

- Percepción positiva por parte de los académicos. (p. 36) 
La intencionalidad funcional y operativa de la contabilidad patrimonial, encaminada a la medición del beneficio verdadero, que intervenía en abstracto unos hechos del pasado, sobre la base del costo histórico, en dirección a desarrollar una visión autosuficiente de veracidad económica con una finalidad concreta, la toma de decisiones operativas, será desplazada por la utilidad de la información orientada principalmente al inversor bursátil y en la cual participan una multiplicidad de usuarios, esencialmente con un carácter "predictivo y confirmatorio" o de pronóstico, relegando o subordinando las necesidades de los restantes usuarios; en este orden de ideas, la perspectiva:

Del beneficio verdadero tiene una gran preocupación por la correcta determinación de los resultados de las actividades ejecutadas por las organizaciones empresariales, por la medición de la ganancia, de la verdadera dimensión de creación de riqueza, y recientemente por la medición de la distribución de la riqueza en el modelo económico. (Franco, 2010, p. 28)

De allí que sea evidente que la regulación esté siendo estructurada alrededor de los mercados de capitales, con lo cual se haría necesario la concreción de reglas estandarizadas emitidas por organismos de carácter privado; así entonces, el capitalismo financiarizado contemporáneo define una orientación regulativa contable mercadocentrista que se profundiza acorde con los requerimientos de la arquitectura financiera internacional (Gómez, 2004). La regulación contable internacional, como tecnología económica, responde exclusivamente a las leyes del mercado, convirtiéndose en una forma de gestión de la vida económica de las empresas, las organizaciones y la sociedad (gubernamentalidad).

Como puede inferirse, el criterio utilitarista de esta versión normativa contable, no tendrá dentro de su agenda como preocupación la verificabilidad y objetividad de la información, sino, y ante todo, resaltará la relevancia de la información, la cual se refiere a la notoria capacidad potencial que pueda desarrollar de cara a influenciar las decisiones en contextos de incertidumbre; de allí que reclame metodológicamente estructurar criterios de predictibilidad de la información, sobre todo en productos como, por ejemplo, los derivados, principales instrumentos financieros que, entre otras de sus funciones, permiten anticipar o cubrir riesgos frente a los cambios futuros, minimizando la contingencia de las situaciones adversas; en este sentido, la utilidad se constituye en un dispositivo de predicción.

Ahora bien, si el costo histórico para efectos de su utilización requiere de relaciones entre agentes económicos, atravesadas por la operatividad de factores de producción, el valor razonable restringe su actuación a procedimientos de valuación exentos de relaciones productivas; esto también, de alguna manera, explica por qué desde los centros de producción normativa se prohíja la implantación de prácticas contables anglosajonas hacia la 
Narváez, V. y Oviedo, J. Imperio, financiarización y los nuevos centros de producción normativa contable

mayoría de economías de occidente a través de intentar desarrollar procesos de convergencia entre las International Financial Reporting Standards (IFRS) del International Accounting Standards Board (IASB) y el resto de economías del mundo capitalista occidental, desconociendo las singularidades de muchos de los contextos de los países emergentes en los que su base económica está soportada en las pequeñas y medianas empresas de base patrimonial.

En un escenario financiarizado y fluctuante, la información basada en datos históricos poco sirve para predecir situaciones futuras; por tanto, habrá que ajustar tales mediciones utilizando formas encubiertas de "valoración" como el denominado valor razonable, que en esencia no es un valor sino un precio de mercado, pues tal como lo definen las organizaciones de regulación privada, tanto el IASB en la NIIF 13 (IASB, 2014, párrafo 9), como el Financial Accounting Standards Board (FASB) en el Statements of Financial Accounting Standards (SFAS) 157 (FASB, 2006, párrafo 5), en donde se precisa que el valor razonable es "el precio que sería recibido por vender un activo o pagado por transferir un pasivo en una transacción ordenada entre participantes del mercado a fecha de la medición”, o como bien lo describe Rafael Franco (2010):

La revelación de información es objeto de un tratamiento selectivo y se resuelve por la producción de informes en diferentes bases de valuación, destacándose la importancia de plantear una alternativa al costo histórico constituida por información del futuro relacionada con planes y presupuestos, estableciendo la puerta de entrada al valor razonable. (p. 29)

Con esta incongruencia conceptual y epistémica, se genera un vacío en términos de aprehensión de la realidad económica y de la circulación de la riqueza, debido a la ausencia de herramientas o instrumentos idóneos de medición y valoración, que conducen a generar un ambiente incierto e inestable al momento de conocer la real situación de la empresa.

Por otra parte, la información contable deberá llegar oportunamente a los usuarios, con el propósito de poder obtener utilidad para tomar decisiones estratégicas que permitan diferenciar a los diversos actores que compiten en el mercado. Este enfoque utilitarista comporta problemas, hasta de índole ético, toda vez que abre la posibilidad de construir tantos sistemas contables a cuantos usuarios de la información financiera se presenten, o como bien lo expresa Montesinos (1974), cuando especifica la direccionalidad que adquiere esta propuesta empírica: "1. Suponer que los estados financieros se preparan para usuarios indeterminados, que tienen objetivos múltiples, 2. Concretar como objetivo el proporcionar información adecuada a modelos para decisiones de usuarios específicos" (p. 274).

De igual manera, las transformaciones de la economía contemporánea, que en cierta medida de-sustancializan lo tangible, ha transferido a los intangibles y a la especulación la facultad para la generación de valor, así como la obtención 
de beneficios futuros. Por esta razón, el concepto de utilidad de la información financiera está vinculado a la incertidumbre futura, en lo concerniente a la capacidad de elección decisional. Así las cosas, el objetivo perseguido por cualquier empresa, al momento de elaborar la contabilidad financiera, deberá ser la de proporcionar información útil a los usuarios de esta para adoptar decisiones eficientes en un mundo de riesgo y de contingencias inevitables:

...en esta nueva forma de gobierno de la empresa, para el accionista, la doctrina central de la gestión es la maximización del valor. El valor, ahora, se genera y distribuye (concentra) en los mercados financieros. De esta manera, la empresa se transforma y se convierte en un engranaje vital del proceso de financiarización. (Gómez, 2016, p. 13)

Así entonces, se le ha catalogado en los círculos hegemónicos contables metropolitanos, llámese IASB o FASB, como una verdadera revolución de los entramados conceptuales de la contabilidad, pero tales apreciaciones constituyen narrativas que poseen una clara intencionalidad dominadora de la esfera informativa contable, como bien lo expresa Müller (2014):

Se han producido cambios profundos en la regulación de la contabilidad financiera y, las NIIF son sólo una parte, aunque muy importante. Se han provocado proclamas de una "revolución contable" o un "cambio de paradigma". Tales afirmaciones pueden ser exageradas, pero estamos efectivamente presenciando un cambio cualitativo y sistemático en lugar de una serie de modificaciones inconexas que dejen intacta la naturaleza fundamental del sistema contable. Este cambio tiene dos aspectos importantes: el primero se refiere a la gobernanza de la regulación contable. Aquí hemos visto el desplazamiento de la soberanía de las instituciones reguladoras nacionales a un cuerpo privado transnacional, en gran medida inexplicable. El otro se refiere al contenido de la regulación contable, es decir, a los principios y objetivos que informan la normalización contable. (p. 539)

Tanto los trabajos del FASB y del IASB no son producto de una neutralidad axiológica, sino que tienen una intencionalidad política hegemónica. La triada conocimiento, poder y verdad, ha demostrado ser indisoluble cuando se trata del aprovechamiento rentístico que produce y reproduce consuetudinariamente el sistema capitalista de acumulación, del cual la contabilidad es su estructura racionalizadora.

\section{Modelo internacional hegemónico de regulación contable en pymes}

El modelo hegemónico de regulación implantado por el IASB, que tiene como sustento, en teoría, el Marco Conceptual para la Información Financiera tanto para las NIIF plenas, como para la NIIF para pymes, enuncia que contribuye con la misión de la Fundación IFRS en cuanto al desarrollo:

...de normas que aporten transparencia, rendición de cuentas y eficiencia a los mercados financieros de todo el mundo (...) El Marco Conceptual proporciona el 
Narváez, V. y Oviedo, J. Imperio, financiarización y los nuevos centros de producción normativa contable

fundamento para elaborar Normas que: (...) c) Contribuyen a la eficiencia económica ayudando a los inversores a identificar oportunidades y riesgos en todo el mundo, mejorando así la asignación de capital. (IASB, 2018, SP1.5)

Está claro que las pymes difícilmente evolucionan hasta llegar a actuar en los mercados financieros y por otra parte tienen dificultades en la inyección de capital. En este sentido, Barquero (2003), sostiene que las pymes presentan como principales problemas la estructura financiera, la escasez de capital de trabajo operativo y el personal no calificado.

Las pymes, como motores de la economía, tienen ciclos de vida cortos y demandan información en relación con el entorno para la toma de decisiones y el funcionamiento de procesos internos (Sánchez y Giraldo, 2008); muchas de ellas son satélites de las grandes firmas, en las que se ha descentralizado el trabajo fabril y de servicios. Podrían asemejarse a las áreas o secciones en las que, en otrora mega fábricas fordistas, destinaban recursos y articulaban en un complejo sistema creador de valor al interior de estas. Sin embargo, subsisten en un ambiente competitivo para permanecer articuladas a estas cadenas de valor. No obstante, otras responden a economías de subsistencia que se desenvuelven en el sector informal.

El término pymes es muy amplio e incluye un abanico de posibilidades que van desde el volumen de los activos hasta el número de empleados de las que cada jurisdicción las define como tal. Las pymes representan entre el $96 \%$ y el $99 \%$ de las empresas en la economía, según datos de la OCDE, y a pesar de esta cifra, la Unión Europea no obliga a las pymes dentro de su jurisdicción a implantar la NIIF para pymes. Esto resulta coherente con la restricción del costo que representa para muchas de ellas aplicar alguna de las secciones de esta norma, sumado a que el objetivo emanado de esta noma sea brindar información "útil a los inversores, prestamista y otros acreedores existentes y potenciales para tomar decisiones sobre el suministro de recursos a la entidad" (IASB, 2018, 1.2); información con fines externos que poco o nada resulta relevante y útil a los propietarios administradores, porque tal como lo enuncia el mencionado Marco Conceptual: "la gerencia no necesita confiar en informes financieros con propósito general porque es capaz de obtener la información financiera que necesita de forma interna" (IASB, 2018, 1.9).

$\mathrm{Al}$ analizar el objetivo de la información financiera descrito en el párrafo anterior, propuesto en el Marco Conceptual del IASB (2018), encontramos que el mismo se centra en proporcionar información financiera útil para la toma de decisiones y está sustentado en una serie de características que debe cumplir la información financiera para cumplir dicho objetivo: relevancia, representación fiel, comparabilidad, verificabilidad, oportunidad y comprensibilidad. Sin embargo, no hay una plena garantía de que estas características se puedan cumplir a cabalidad en las todas las entidades y especialmente en las pymes, 
puesto que existen factores particulares dentro de cada país y región que pueden generar matices dentro de la aplicación de los estándares, al respecto (Zeff, 2007) menciona que existen al menos cuatro tipos de culturas -financiera y de negocios, contable, de auditoría y regulatoria- que difieren de un país a otro y que se convierten en factores que pueden interferir con la promoción de la comparabilidad genuina a nivel mundial.

Frente a estas divergencias que se pueden encontrar en el momento de aplicar estándares internacionales, se abre un interrogante a la hora de definir si efectivamente la información financiera es útil para la toma de decisiones, más aún bajo la óptica de los nuevos centros de producción normativa contable, que generan una serie de laxitudes a la hora de su aplicación; encontramos así, por ejemplo, que con el predominio actual de valor razonable, las entidades pueden reconocer ingresos no realizados, distribuir resultados no generados y los modelos de valoración de flujos futuros están por encima de los precios de mercado, lo que puede llevar a una sobrestimación de activos o de ingresos; a esta situación se llega como resultado del desmonte de valores y principios tales como prudencia, objetividad, independencia y fiabilidad (Gómez, 2010).

La presencia del valor razonable implica que en las cuentas se mezclan datos que representan tanto transacciones realizadas como supuestos sobre el futuro, "la aplicación del valor razonable no informa tanto sobre la capacidad de una empresa para generar beneficios económicos en el futuro, como sobre lo que podría reportar su liquidación inmediata, su desmembramiento en unidades" (Aglietta y Rebérioux, 2009, 170). Esta situación afecta la toma de decisiones debido a que la información que brinda el valor razonable, podría llegar a que en algunas circunstancias no se represente de manera fiel la situación de las organizaciones. Los estándares de información financiera orientados hacia la predicción trasgreden algunos principios tradicionales de contabilidad como la prudencia, al permitir el reconocimiento de beneficios que no son reales, sino expectativas futuras; el costo histórico ha sido desplazado y es reemplazado por el valor razonable, el cual se considera un criterio de valoración más relevante, pero se encuentra sujeto a las distorsiones propias de los mercados de capitales.

Lo anterior devela que el valor razonable pregonado en este tipo de regulación para empresas que cotizan en bolsa es poco aplicable a las pymes cuyas necesidades de información difieren sustancialmente. Es por esto que esta regulación se distancia del suministro de información propia de los procesos de producción de la economía real para ser funcional a la reproducción de la financiarización (Gómez, 2004), lo cual margina características propias de la contabilidad como sistema de información intraempresarial. 
El costo histórico como medición primaria y sobre la cual se difiere, para la propiedad planta y equipo, a lo largo del tiempo la inversión, representa para los productores reales un referente de productividad de este tipo de "activos productivos", mientas que la actualización -medición posterior- que exige la sección 17 de la NIIF para pymes distorsiona este indicador al incluir el deterioro tanto en el modelo del costo como en el modelo de revaluación. En este sentido la verificabilidad y objetividad del costo histórico se subordina, en el mejor de los casos, a la información emanada de mercados activos, baluarte de la regulación propuesta por el IASB. Mauricio Gómez (2016) expone otros tratamientos asimétricos en las NIIF para pymes los cuales impactan la realidad económica de las pymes y por tanto su eficiencia y competitividad frente a las grandes empresas.

A pesar de esto, la regulación contable internacional hegemónica, con complacencia de los gobiernos nacionales, se empeña en adherir estas pequeñas unidades productoras a los procesos de internacionalización financiarizando sus actividades, ya sea aplicando sus principios -no reglas- en la financiación de largo plazo como en la financiación de capital de trabajo. En esta etapa, como se ha visto, se vienen desarraigando prácticas locales mediante el lenguaje para establecer nuevos códigos. El Discurso del emprendimiento requiere general aceptación de tal manera que se implante en su visión la necesidad imperiosa de mercados internacionales y de hacerse visible para la apertura de potenciales inversiones extranjeras.

En este escenario, los flujos de capital buscan optimizar la relación riesgo y rendimiento; el riesgo financiero prima sobre el riesgo operativo y el rendimiento accionario sobre la utilidad operativa y para esto se hace necesario, más que converger, instaurar las reglas basadas en principio establecidas en el nuevo escenario de utilidad para toma de decisiones de des/ inversión.

La captación, medición, representación, revelación e interpretación, bajo la racionalidad del capital, requieren de herramientas unívocas normativizadas de las que se espere la mejor estimación posible de los entes que informan moldeando la contabilidad y el quehacer de los contables, que han visto cómo sus objetivos paulatinamente han sido direccionados hacia el control de información previamente definida, dejando de lado su criterio profesional y develando el carácter compilatorio de la regulación internacional al servicio de los capitales transnacionales que buscan, infructuosamente para el caso de las pymes - sin usuarios de información en los mercados financieros-, articular y/o captar su innovación y productividad como nodos de la redes con las que se modelan pronósticos de las multinacionales en las pantallas chartistas, distorsionando la información emitida que, contrario a mejorar su calidad, desnaturaliza el objeto y deber real de la pymes en economías locales. 


\section{VI.Conclusiones}

Los grandes cambios suscitados en la economía global, y el ascenso al poder de las finanzas de mercado, han modificado de manera sustancial las relaciones de poder a nivel mundial, generando un desplazamiento de la hegemonía de los Estados-nación y más concretamente un reordenamiento de la función reguladora del Estado en manos de una serie de organismos supranacionales que se han otorgado el poder para emitir normas y regular el mercado; en este contexto la NAFI se consolida como el agente por excelencia para emitir normas de carácter financiero a nivel internacional que privilegian los interés de ciertos actores de los mercados financieros, como es el caso de las NIIF. De igual manera, la contabilidad como instrumento de racionalidad del capital no ha escapado a las trasformaciones de los sistemas de producción y de los cambios en las relaciones de poder; es así como la contabilidad patrimonial que intervenía los hechos del pasado, sobre la base del costo histórico y que tenía como finalidad generar una veracidad económica para la toma de decisiones, ha sido desplazada por una contabilidad con un carácter predictivo y de pronóstico, fundamentada en el criterio de utilidad de la información que se orienta principalmente a los inversionistas, desplazando las necesidades de otros usuarios de la información.

En estos nuevos escenario de amenaza constante de la profesión contable $\mathrm{y}$ ante los recientes sucesos catastróficos, de proporciones globales, que recuerdan la importancia de las relaciones de producción material y la satisfacción de necesidades básicas, concierne a los contadores incursionar, ampliando su espectro de acción, en otros quehaceres de la profesión que han sido invisibilizados por la ola de la regulación de la contabilidad financiera internacional, y que lejos de normativizarse proporcionan información diversa, útil y relevante a los propietarios administradores de unidades productivas del sector real de la economía, facilitando el proceso de toma de decisiones que beneficien al grueso de la sociedad.

\section{Referencias bibliográficas}

Aglietta, M. y Rebérioux, A. (2009). El capitalismo financiero a la deriva El debate sobre el gobierno de empresa. Bogotá: Universidad Externado de Colombia.

Barquero, I. (2003). El estado y la Competitividad de la Micro pequeña y mediana empresa. Primera edición ed. Tegucigalpa: Colección cuadernos de desarrollo humano sostenible 21.

Burgos, G. (2000). El Banco Mundial y su análisis del derecho y el poder judicial. ¿De qué Estado de Derecho nos habla el Banco Mundial? 1992-1998. En: La mano invisible del mercado. Derecho y Economía. Bogotá: ILSA, pp. 47-95.

Castells, M. (2000). La Sociedad Red. Madrid: Alianza Editorial S.A.

Cortés, J. y Álvarez, H. (2018). La supra regulación contable y la financiarización económica. Revista En Contexto, pp. 61-87. 
Narváez, V. y Oviedo, J. Imperio, financiarización y los nuevos centros de producción normativa contable

De Sousa Santos, B. (1998). La Globalización del Derecho. Los Nuevos Caminos de la Regulación y la Emancipación. Bogota D.C.: Universidad Nacional de Colombia, Instituto de Servicios Legales Alternativos.

Deleuze, G. y Guattari, F. (2002). Mil Mesetas. Capitalismo y Esquizofrenia. Valencia: Pretextos.

Eichengreen, B. (1999). Toward a New International Financial Architecture: A Practical Post-Asia Agenda. Washington DC: Institute for International Economics.

FASB. (2006). FASB Statement No. 157, Fair Value Measurements. Norwalk: Financial Accounting Foundation.

Feudal, O. y Linares, H. (2006). Diferentes escenarios y antecedentes de la evolución del pensamiento contable. Contabilidad y Auditoría, (24) 15 pp. Recuperado a partir de http://ojs.econ.uba.ar/index.php/Contyaudit/article/view/117

Franco, R. (2010). De la crisis del paradigma de utilidad a la emergencia del enfoque integral. Revista Dictamen Libre, Volumen 6, pp. 20-45.

Franco, R. (2015). Dimensión heterotopológica de la regulación contable. Perspectivas críticas sobre gobierno corporativo y regulación, Revista Científica General José María Córdova, Volumen 13, pp. 173-199.

Gómez, M. (2004). Una evaluación del enfoque de las Normas Internacionlaes de Información Financiera (NIIF) desde la teoría de la contabilidad y el control. INNOVAR, 1(24), pp. 112-131.

Gómez, M. (2010). Interés público y ejercicio de la Contaduría Pública: Miradas al contexto internacional y aprendizaje para la profesión en Colombia. Revista Unimar, pp. 77-90.

Gómez, M. (2016). NIIF y Mipymes: Retos de la Contabilidad para el contexto y la productividad. Cuadernos de Administración, 29(53), pp. 49-76.

Hardt, M. y Negri, T. (2002). Imperio. Buenos Aires: Paidós.

IASB. (2013). NIIF 13. Medición del valor razonable. London: International Financial Reporting Standards Foundation.

IASB. (2018). Marco conceptual para la información financiera. London: International Financial Reporting Standards Foundation

Ilich, V. (1975). El imperialismo, fase superior del capitalismo. Pekín: Ediciones en lenguas extranjeras.

Medialdea, B. y Sanabria, A. (2013). La financiarización de la economía mundial. Hacia una caracterización. Revista de Economía Mundial, pp. 195-227.

Mignolo, W. (1993). Colonial or Postcolonial Discourse: Cultural Critique or Academic Colonialism. Latin American Research Review, 28(3), pp. 120-134.

Montesinos, V. (1974). Contabilidad y decisión empresarial: una aproximación conceptual. Valencia: Facultad CC.EE.

Muller, J. (2014). An accounting revolution? The financialisation of standard setting. Critical Perspectives on Accounting, 25(7), pp. 539-557.

Pardo, S. (2017). Evaluación crítica de la pertinencia del valor razonable y el gobierno corporativo anglosajón para el control en las organizaciones en Colombia. Repositorio Institucional de Alejandría. 
Sánchez, A. y Giraldo, N. (2008). Las necesidades de las pyme -pequeñas y medianas empresas- y el sistema de información contable y financiero como una estrategia para atenderlas. Cuadernos de Contabilidad, 9(25), pp. 421-464.

Sassen, S. (2010). Territorio, autoridad y derechos. De los ensamblajes medievales a los ensamblajes globales. Buenos Aires: Katz Editores.

Schwarcs, S. L. (2002). Private ordening. Northwestern University law Review, 97(1), pp. 319-350.

Slater, D. (2008). Re-pensando la geopolítica del conocimiento: reto a las violaciones imperiales. Tabula Rasa, Volumen 8, pp. 335-358.

Tua Pereda, J. (1991). La investigación empírica en contabilidad Los enfoques en presencia. Revista de Economía y Estadística, Cuarta época, 32(1-2), pp. 3-83.

Zeff, S. (2007). Some obstacles to global financial reporting comparability and convergence at a high level of quality. The British Accounting Review, 39, 290-302. 